\title{
Airborne particle granulometry and micromorphology during working and not working days in the Brussels environment
}

\author{
P. Vanderstraeten ${ }^{1}$, Y. Lénelle ${ }^{1}$, A. Meurrens ${ }^{1}$, D. Carati $^{2}$, \\ L. Brenig ${ }^{2} \&$ Z. Y. Offer ${ }^{3}$ \\ ${ }^{1}$ Institute Bruxellois pour la Gestion de l'Environnement, Brussels \\ Instituut voor Milieubeheer, Belgium \\ ${ }^{2}$ Université Libre de Bruxelles, Belgium \\ ${ }^{3}$ Ben-Gurion University, Beersheva, Israel
}

\section{Abstract}

We report and analyze here data on airborne particles up to PM10, measured in the Brussels region from October 2002 through to September 2003.

The purpose of this study was to measure the impact of urban activities on airborne particles. Differences in the granulometry and micromorphology of particles sampled on working days and weekends were studied. Two parameters are computed for a large number of collected particles. The first parameter is the isoperimetric quotient, IQ, defined as the area $\mathrm{A}$ of the planar projection of the particle divided by the square of its perimeter (rescaled by $4 \pi$ ), i.e. $\mathrm{IQ}=4 \pi A / p^{2}$. This parameter is smaller or equal to one (for a circular planar projection) and measures the particle surface irregularity or roughness.

The second parameter, $\beta$, corresponds to the ratio $\mathrm{L}_{1} / \mathrm{L}_{2}$ between the projected major and minor axis of the particle. It is larger or equal to one and represents the particle elongation.

We observed significant tendencies in the particles distributions in terms of IQ and $\beta$.

Keywords: airborne particle, granulometry, micromorphology, Brussels environment. 


\section{Introduction}

There has been growing interest recently in the study of airborne particulate matter, more especially towards improved understanding of the long-term transport and impact of different elements of the lithosphere and atmospheric pollution. Around ground level, a fairly thin layer of the lithosphere and atmosphere, on both sides of their interface, serve as the major platform for life and civilization. Both the lithosphere and the atmosphere are mutually responsible for sustaining their productive equilibrium. Airborne dust is a mainly mineralogical component of the lithosphere that periodically but temporarily upholds that equilibrium.

The investigation of atmospheric air components is integrated into the global ecology perception and is part of the science of the environment, which includes all the phenomena that are involved in the relationship between human society and the vital environment [18]. Data on grain size and its distribution in Aeolian dust is abundantly available in the literature. Most of the data concern shortterm periods (usually dust storms or other events of high dust activity) [5, 8, 13$15,17]$ or medium-term data evolution [9-11, 19]. As for horizontal dust flux, published long-term information for dust grain size is only available via indirect studies, for example, dust in oceanic sediment cores $[3,6,21]$, in ice cores $[12$, $22,23]$, or in loess deposits [1, 4, 7, 26]. Arimoto et al. [2] performed grain size measurements of airborne dust collected over the Atlantic and Pacific oceans.

Related to the EC Directives, in 1996, the EC issued a new frame directive $(1996 / 62 / C E)$ for the assessment of ambient air quality.

One of the actual EC limit values on PM10, a daily value of $50 \mu \mathrm{g} / \mathrm{m}^{3}$ not to be exceeded more than 35 times per year, from 2005 on, is not respected in all sites of the Brussels Capital Region, as is the case for many cities in dense populated areas of Western Europe. A new proposal for limiting the PM2,5 exposure, still under discussion, will be also hard to fulfill. So it is of importance that additional information is gathered in order to understand somewhat better the physico-chemical reality in this complex phenomenon.

More generally, our work illustrates a new methodology to analyze specific aspects of the dynamics of the airborne particles by combining the in situ measurements, the laboratory investigation on the granulometry and micromorphology along with the statistical analysis.

\section{Methodology and experiment design}

PM10 measurements in the Brussels-Capital Region, using continuous monitoring, are more recent than the measurements for the gaseous pollutants. Started in 1996 with two PM10-systems (oscillating microbalance R\&P TEOM 1400-Ab), the network now contains six PM10 monitors. These analyzers are installed in Molenbeek, Uccle, Haren, Berchem, Meudon Parc and Woluwe. By mid-2000, three PM2,5 monitors of the same type were installed in: Molenbeek, Haren and Meudon Park. The PM2,5 sampler consists of a PM10 impactor followed by a PM2,5 cyclone. At two of these stations (Uccle and Woluwe) and 
at the University (ULB-Campus Plaine), additional sampling (Airborne Particle Samplers) was carried out on filter membranes for the examination of physical and chemical properties of the airborne particles [24].

For the present research, a SEM (Phylips scanning electron microscope) was used for the determination of the composition of the particulates sampled on Saturdays, Sundays and Mondays. Because the SEM energy dispersive technique can focus on very small particles and resolve even trace amounts, we consider its determination as reliable.

The analysis of particle morphology is of special importance since particle shape distribution is expected to directly affect transport and the mechanisms of deposition - accumulation as well as the impact with the ground surface.

Using SEM instrument (type JSM 5410 JEOL), a series of quantities have been measured on a large number of particles, the projected surface (A, in $\mu \mathrm{m} 2)$, the projected perimeter $(\mathrm{P}$, in $\mu \mathrm{m})$ and the projected major and minor axis $\left(\mathrm{L}_{1}\right.$ and $\mathrm{L}_{2}$ in $\mu \mathrm{m}$ ).

On each filter, between 100 and 200 particles were selected in function of the density of the particles on the same portion of the filters. In order to identify the value of the projected area and the form of the particles (especially the very small ones), the filters were analyzed at various resolutions (magnitudes). On the filters, the micromorphology of the airborne particles has been analyzed by computerized SEM investigation using a Soft Imaging System (SIS - digital solutions for imaging and microscopy).

\section{Statistical analysis}

As the variability among the filters was high, the total amount of particles, (approximately 160) for each day, was sorted according to the area, in order to divide all the data into 3 size groups. The average $(\bar{X})$ and half of the standard deviation $(\sigma / 2)$ were the data indicators used to make this data division. The following equations indicate the limits of each size group:

Size Group 1: $\quad 0 \rightarrow(\bar{X}-\sigma / 2)$

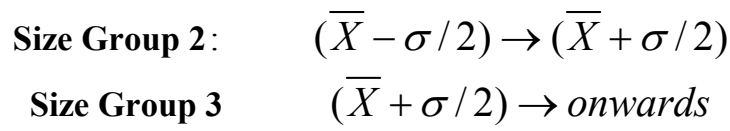

In some Month - Day - Station data sets, a small number (one, two or three) of very big particles, having great impact on the standard deviation, were pulled out of the series in order to make the first size group suitable (limit $\left.1 \mu \mathrm{m}^{2}\right)$. As the amounts of analyzed particles in each size group were different between the stations and between the months, weighted averages had to be calculated to represent the fluctuations between different days. 
A monthly weighted average was computed to identify the fluctuations throughout the year. For each month, average area of each size group was calculated according to the equation:

$$
M W A=\frac{\sum\left(\bar{X}_{k} \cdot \boldsymbol{n}_{k}\right)}{N_{k}}
$$

with the following definitions:

$M W A: \quad$ month weighted average among the three stations

$\bar{X}_{k}: \quad$ station area average

$n_{k}:$ amount of particles of station

$N_{k}: \quad$ total amount of particles

$k \quad$ : each station

As every average area was already weighted by the amount of particles in each day and group, the All Stations "Day" average corresponds to the simple average between the three stations.

In order to characterize the shape of the particles, the ratio of projected major and minor axis $(\beta)$ of the particles and the Isoperimetric Quotient (IQ) were calculated. The IQ represents how rounded a certain figure is and is given by the following equation:

$$
I Q=\frac{4 \pi \cdot A}{p 2}
$$

where:

$\boldsymbol{A} \quad$ : $\quad$ Particle projected area

p : $\quad$ Particle projected perimeter

The difference with the area analysis is that the variation of these indices is much smaller than for the area, therefore only the average value for each index was considered and no different groups were searched.

\section{Results}

The analysis was performed in order to characterize the difference in area and shape of dust particles collected by the three stations (UCCLE, ULB and IBGE BIM) for Saturdays, Sundays and Mondays during the period September 2002October 2003.

Among the particles that have been analyzed a large number (about 50\%) are characterized by $0.7<$ IQ $<1$ while about $40 \%$ correspond to $1.0<\beta<1.5$. 
Particle micromorphology analysis shows that many particles have a rather small elongation ( $\beta$ between 1 and 1.5) while particles having a projected surface large than $10 \mu \mathrm{m}^{2}$ are more elongated ( $\beta$ around 2 ) than the smaller ones. This tendency could be due to the fact that larger particles are often aggregates [24].

Table 1: Particles Area, Major-Minor axis ratio $\mathrm{L}_{1} / \mathrm{L}_{2}$ and Isoperimetric Quotient (IQ) averages, by days, stations and, months.

\begin{tabular}{|c|c|c|c|c|c|}
\hline & Factor & $\mathbf{n}$ & $\begin{array}{c}\text { Area } \\
\left(\mu \mathrm{m}^{2}\right)\end{array}$ & $\mathbf{L}_{\mathbf{1}} / \mathbf{L}_{\mathbf{2}}$ & IQ \\
\hline Days & $\begin{array}{l}\text { Saturday } \\
\text { Sunday } \\
\text { Monday }\end{array}$ & $\begin{array}{l}3160 \\
2628 \\
3107\end{array}$ & $\begin{array}{l}7.83 \\
7.51 \\
7.55\end{array}$ & $\begin{array}{l}1.52 \\
1.57 \\
1.52\end{array}$ & $\begin{array}{l}0.536 \\
0.533 \\
0.535\end{array}$ \\
\hline Stations & $\begin{array}{c}\text { IBGE } \\
\text { UCCLE } \\
\text { ULB }\end{array}$ & $\begin{array}{l}3261 \\
2919 \\
2715\end{array}$ & $\begin{array}{l}7.37 \\
8.43 \\
7.13\end{array}$ & $\begin{array}{l}1.55 \\
1.52 \\
1.53\end{array}$ & $\begin{array}{l}0.531 \\
0.533 \\
0.541\end{array}$ \\
\hline \multirow[t]{2}{*}{ Months } & $\begin{array}{l}\text { October } \\
\text { November } \\
\text { December } \\
\text { January } \\
\text { February } \\
\text { March } \\
\text { April } \\
\text { May } \\
\text { June } \\
\text { July } \\
\text { August } \\
\text { September }\end{array}$ & $\begin{array}{c}850 \\
1000 \\
877 \\
688 \\
613 \\
1233 \\
952 \\
1149 \\
673 \\
288 \\
259 \\
313\end{array}$ & $\begin{array}{l}8.03 \\
8.37 \\
7.00 \\
5.81 \\
7.37 \\
9.87 \\
7.42 \\
7.00 \\
8.30 \\
5.78 \\
6.43 \\
6.15\end{array}$ & $\begin{array}{l}1.45 \\
1.50 \\
1.46 \\
1.48 \\
1.62 \\
1.52 \\
1.55 \\
1.62 \\
1.60 \\
1.61 \\
1.53 \\
1.54\end{array}$ & $\begin{array}{l}0.528 \\
0.525 \\
0.536 \\
0.535 \\
0.512 \\
0.532 \\
0.538 \\
0.547 \\
0.548 \\
0.522 \\
0.547 \\
0.552\end{array}$ \\
\hline & Average & & 7.64 & 1.53 & 0.535 \\
\hline
\end{tabular}

As can be seen from Table 1, no statistical difference was observed in the area of the particles between the studied days. This means that the average particle area for each of these three days should be considered as the weighted average of $7.64 \mu \mathrm{m}^{2}$. A different situation was observed when analyzing the area that was 
collected in each station. UCCLE showed the biggest particles with a surface of $8.43 \mu^{2}$, but no difference was observed between IBGE and ULB.

Regarding the particles shape, (see Table 1) it can be seen that significant differences were found between the $\mathrm{L}_{1} / \mathrm{L}_{2}$ ratio of Sunday's particles in comparison to Saturday's and Monday's particles. Specifically Sunday's particles are statistically longer than the particles of other days. No statistically differences were found between the stations regarding the IQ ratio. More precisely, for the Isoperimetric Quotient, a significant statistical difference was seen between the monthly averages, while no relevant difference appeared between the three stations.

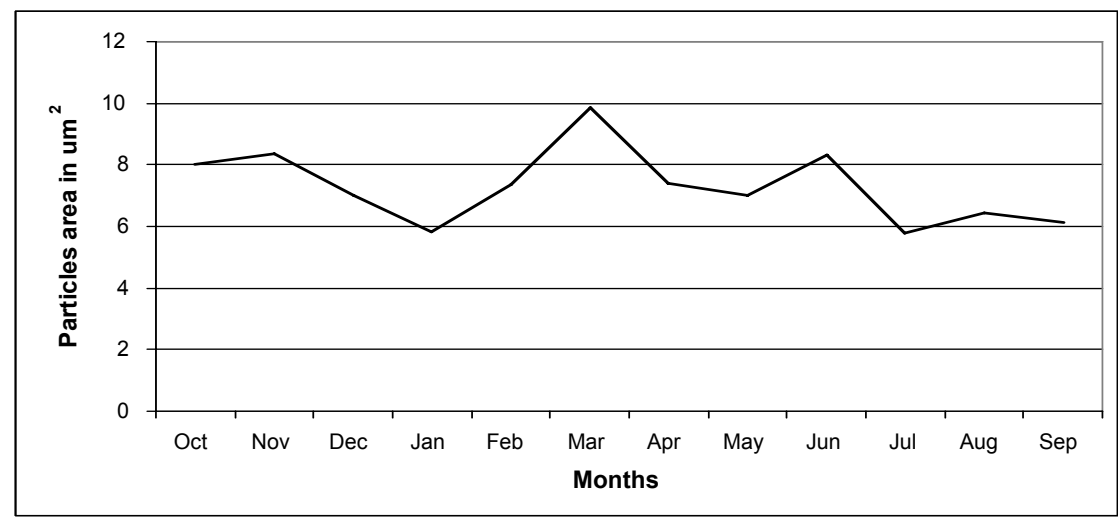

Figure 1: Monthly fluctuation of the particles area (October 2002 September 2003).

From Figure 1 a decrease in the particle size during the 2002 - 2003 winter can be observed. Toward the end of the winter a big increase occurred, which gradually decreased during the spring and summer, arriving at the end of the summer to particle sizes similar to those in the middle of the winter.

As can be seen on Figure 2, although many of the particles appear to have both parameters IQ and $\beta$ quite close to unity, it appears clearly on this plot that both parameters are important for characterizing the particles since they are fairly poorly correlated.

\section{Discussion}

In this study we analyzed the principal components of airborne solid particles in the Brussels region, especially the smaller particle size population (up to 2-3 $\mu \mathrm{m}$ ) that are associated with a higher risk for public health. Concerning the particle size distribution, for all the stations and for the entire studied period, the investigation shows that the smaller particles (less than $1 \mu \mathrm{m}$ ) are by far the most numerous $(61.3 \%)$; particles between $1-3 \mu \mathrm{m}$ registered an average of $28.8 \%$ 
and those between 3-10 $\mu \mathrm{m}$ correspond to $9.2 \%$. Particles greater than $10 \mu \mathrm{m}$ are rare and appear accidental $(0.7 \%$ on average) (see Table 2$)$.

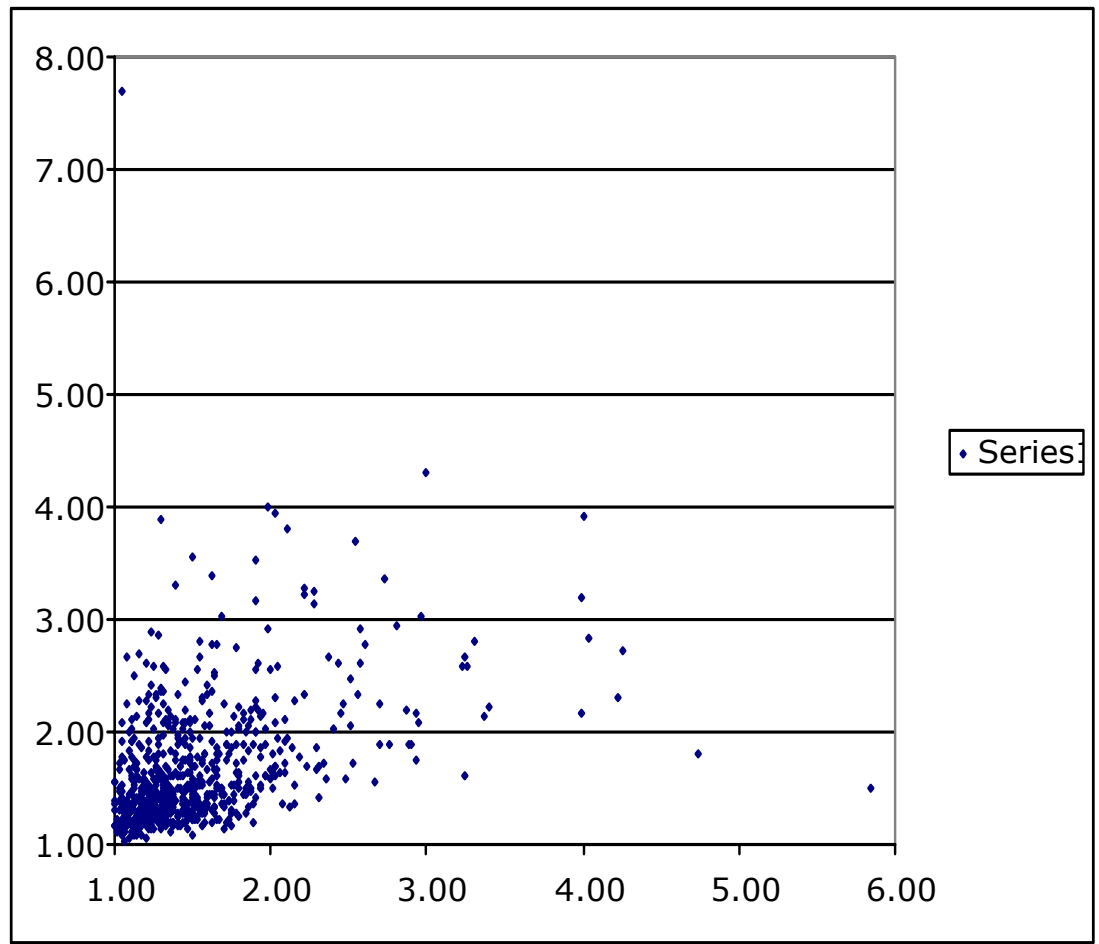

Figure 2: $\quad$ Scatter plot of 1/IQ versus $\beta$.

Table 2: $\quad$ Particle size distribution (\%).

\begin{tabular}{|l|c|c|c|c|}
\hline Station & $<1 \mu \mathrm{m}$ & $1-3 \mu \mathrm{m}$ & $3-10 \mu \mathrm{m}$ & $>10 \mu \mathrm{m}$ \\
\hline Woluwe & 61.5 & 30 & 8.0 & 0.5 \\
\hline ULB & 64.3 & 27.5 & 7.3 & 0.9 \\
\hline Uccle & 58.0 & 28.8 & 12.5 & 0.7 \\
\hline & & & & \\
Average & 61.3 & 28.8 & 9.2 & 0.7 \\
\hline
\end{tabular}

The laboratory analysis (particle size distributions, mineralogy, chemistry), the statistical comparative studies and the relations with the atmospheric (especially advective) dynamics [20], lead to a preliminary conclusion that the 
majority of airborne particles in the Brussels region comes from sources geographically outside the (in situ) Brussels area.

A close similarity of the particle size distributions is observed in the different stations of the Brussels region. This constitutes an argument in favor of a common source for at least a non-negligible part of the particles presence.

A relatively reduced percentage of the particles originate from sources that are inside the Brussels region and are caused by various human activities. These activities are capable of re-suspending particles formerly deposited on different urban surfaces [24].

\section{References}

[1] An Z. and Porter S.C. Millenial-scale climatic oscillations during the last interglaciation in central China. Geology, 25, 603-505 (1997).

[2] Arimoto R., Ray B.J., Lewis N.F., Tomza U. and Duce R.A. Massparticle size distributions of atmospheric dust and the dry deposition of dust to the remote ocean. J. Geophysical Research, 102D, 15867-15874 (1997).

[3] Arnold E.M. The Rock-Magnetic Properties, Grain Size and Mineral Composition of Windborne Dust and Sediment in the North Pacific Ocean. Ph.D. Thesis, University of Rhode Island, 300 pp (1996).

[4] Chen F., Feng Z. and Zhang J. Loess particle size data indicative of stable winter monsoons during the last interglacial in the western part of the Chinese Loess Plateau. Catena, 39, 233-244 (2000).

[5] Chen W. and Fryrear D.W. Grain-size distributions of wind-eroded material above a flat bare soil. Physical Geography, 17, 55-584 (1996).

[6] Clemens S.C. Dust response to seasonal atmospheric forcing: proxy evaluation and calibration. Paleoceanography. 13, 417-490 (1998).

[7] Fang X.M. Rock magnetic and grain size evidence for intensified Asian atmospheric circulation since 800,000 years B.P. related to Tibetan uplift. Earth and Planetary Science Letters, 165, 129-144 (1999).

[8] Gillies J.A., Nickling W.G. and McTainsh G.H. Sedimentological characteristic of an intense dust haze event: Inland Delta region of Mali, West Africa. Atmospheric Environment, 30, 1081-1090 (1996).

[9] Goossens D. and Offer Z.Y. Comparisons of day-time and night-time dust accumulation in a desert region. J. of Arid Environments, 31, 253-281 (1995).

[10] Goossens D. Meteorological and sedimentological analysis of the severe dust storm in the Negev Desert on 2 November 1994. J. Meteorology, 21, 273-286 (1996).

[11] Goossens D., Gross J. and Spaan W. Aeolian dust dynamics in agricultural land areas in Lower Saxony, Germany. Earth Surface Processes and Landforms, 26, 701-720 (2001).

[12] Lorrain R., Sleewaegen S., Offer Z.Y., Azmon E., Firzqimonq, S. and Souchez R. Trapping of eolian sediment in a dry-based Antarctic frozen lake. Earth Surface Processes and Landforms, 27, 307-315 (2002). 
[13] McTainsh G.H., Nickling W.G. and Lynch A.W. Dust deposition size in Mali, West Africa, Catena, 29, 307-322 (1997).

[14] Nickling W.G. Grain-size characteristics of sediment transported during dust storms. J. Sedimentary Petrology, 53, 1011-1024 (1983).

[15] Nickling W.G. and Gillies J.A. Dust emission and transport in Mali, West Africa. Sedimentology, 40, 859-868 (1993).

[16] Nickling W.G., McTainsh G.H. and Leys J.F. Dust emissions from the Channel Country of Western Queensland, Australia. Zeitschrift für Geomorphologie, Suppl. B.D. 116, 1-17 (1999).

[17] Niemeyer, T.C., Gillette D.A., Deluisi J.J., Kim Y.J., Niemeyer W.F., Ley T., Gill T.E. and Ono D. L. Optical depth, size distribution and flux of dust from Owens Lake, California. Earth surface Processes and Landforms, 24, 463-479 (1999).

[18] Odum, E.P. The emergence of ecology as a new integrative discipline, Science, 195, 1289-93 (1977).

[19] Offer Z.Y. and Goossens D. Ten years of aeolian dust dynamics in a desert region (Negev desert, Israel): analysis of airborne dust concentration, dust accumulation and the high magnitude dust events. $J$. Arid Environments, 47, 211-249 (2001).

[20] Offer, Z.Y. Airborne particle dynamics in the Brussels environment. Research in Brussels Actions Report (2002).

[21] Ratmeyer V., Fischer G. and Wefer G. Lithogenic particle fluxes and grain size distributions in the deep ocean of NW Africa: implications for seasonal changes of aeolian dust input and downwards transport. Deep Sea Research, 46, 1289-1337 (1999).

[22] Steffensen J.P. The size distribution of microparticles from selected segments of the Greenland Ice Core Project ice core representing different climatic periods. J. Geophysical Research, 102, 26755-26763 (1997).

[23] Unnerstad L., Hansoon M. Simulated airborne particle size distributions over Greenland during Last Glacial Maximum. Geophysical Research Letters, 28, 287-290 (2001).

[24] Vanderstraeten, P., Lénelle, Y. Meurrens, A, Carati, D., Brenig, L., Offer, Z.Y. 2006. "Granulometry and micromorphology of airborne particles in the Brussels urban environment". Journal of Chemistry and Environment. Proceedings. Pp. 549-571.

[25] Zdanowicz C.M., Zielinski G.A., Wake C.P., Fisher D.A. \& Koerner R.M. A Holocene record of atmospheric dust deposition of the Penny Ice Cap, Baffin Island, Canada. Quaternary Research, 53, 62-69 (2000).

[26] Zhongli D., Rutter N.W., Sun J.M., Yang S.L. and Liu T.S. Rearrangement of atmospheric circulation at about 2.6 Ma over northern China: evidence from grain size records of loess-palaeosol and red clay sequences. Quaternary Science Reviews, 19, 547-558 (2000). 